\title{
Excesso de confiança: análise comparativa da capacidade cognitiva de julgamento entre profissionais de mercado e estudantes de graduação
}

\section{Overconfidence: comparative analysis of cognitive judgment ability between market professionals and undergraduate students}

Sobreconfianza: análisis comparativo de la capacidad de juicio cognitivo entre profesionales del mercado y estudiantes de pregrado

\section{Thais Mota Crabbi}

Mestre em Ciências Contábeis na Universidade de Brasília (UNB)

Professora do Departamento de Ciências Contábeis e Atuariais da Universidade de Brasília (UNB)

Endereço: Campus Darcy Ribeiro s/n, Asa Norte

CEP: 70.910-900 - Brasília/DF - Brasil

Email: thaiscrabbi@gmail.com

Telefone: (61) 98229-2991

\section{Clésia Camilo Pereira}

Doutora em Ciências Contábeis na Universidade de Brasília (UNB)

Professora do Departamento de Ciências Contábeis e Atuariais da Universidade de Brasília (UNB)

Endereço: Campus Darcy Ribeiro s/n, Asa Norte

CEP: 70.910-900 - Brasília/DF - Brasil

Email: clesia@unb.br

Telefone: (61) 3107-0798

\section{César Augusto Tibúrcio Silva}

Doutor em Ciências Contábeis na Universidade de São Paulo (USP)

Professor do Departamento de Ciências Contábeis e Atuariais da Universidade de Brasília (UNB)

Endereço: Campus Darcy Ribeiro s/n, Asa Norte

CEP: 70.910-900 - Brasília/DF - Brasil

Email: cesartiburcio@unb.br

Telefone: (61) 3107-0812

Artigo recebido em 30/12/2018. Revisado por pares em 30/10/2019. Reformulado em 12/12/2019. Recomendado para publicação em 15/12/2019 por Carlos Eduardo Facin Lavarda (Editor-Chefe). Publicado em 30/03/2020. 


\section{Resumo}

A presente pesquisa tem por objetivo verificar a relação do viés cognitivo excesso de confiança entre profissionais de mercado e estudantes de graduação. $O$ procedimento utilizado para coleta de dados foi a aplicação de um questionário com perguntas popularmente conhecidas como questões de conhecimento geral, sendo que, para cada questão, o indivíduo aponta sua confiança na resposta dada. A pesquisa contou com uma amostra de 424 indivíduos das três áreas científicas: Humanidades, Ciências Exatas e Ciências da Vida, sendo 270 estudantes de graduação e 154 profissionais já estabelecidos no mercado de trabalho. Para análise do excesso de confiança foi utilizado o modelo formulado por Murphy (1973), cuja fórmula derivou do Brier Score. Também foram verificadas as relações quanto a calibração, por meio da metodologia de Lichtenstein, Fischhoff e Phillips (1982), e a acuidade, proporção de respostas corretas. Os resultados demonstraram que os profissionais de mercado são mais excessivamente confiantes do que os estudantes de graduação. Os estudantes acertaram proporcionalmente mais questões em cada categoria de confiança, mas obtiveram uma menor calibração em seus julgamentos de probabilidade. Além disso, verificou-se, também, a relação entre o excesso de confiança, acuidade e calibração no tocante a qualificação dos profissionais, à relação entre gêneros feminino e masculino relacionados as três áreas científicas, entre idade, entre os cursos mais representativos da amostra e o grau de dificuldade das questões.

Palavras-chave: Excesso de confiança; Profissionais; Estudantes

\section{Abstract}

The present research aims to verify the relation of the cognitive bias overconfidence between market professionals and undergraduate students. The data collection procedure was done by applying a questionnaire with questions usually known as almanac questions, and for each question, the individual points out their confidence level in the given answer. The research had a sample of 424 individuals from the three scientific areas: Exact Sciences, Life Sciences and Humanities, composed by 270 undergraduate students and 154 already established professionals. The model formulated by Murphy (1973) was applied for the analysis of the excess of confidence, whose formula derived from the Brier Score. Relationships regarding calibration were also verified by using the methodology of Lichtenstein, Fischhoff and Phillips (1982), and acuity, the proportion of correct answers. The results showed that market professionals are more overconfident than undergraduates. Students had more correct answers proportionally in each confidence category but obtained a lower calibration in their probability judgments. In addition, the research concluded about the relationship between overconfidence, acuity and calibration with regard to the specialization of professionals, gender, the three scientific areas and the individual's age, among the most representative courses of the sample and the difficulty level of the questions. Keywords: Overconfidence; Professionals; Students

\section{Resumen}

La presente investigación tiene por objetivo verificar la relación del sesgo cognitivo exceso de confianza entre profesionales de mercado y estudiantes de graduación. El procedimiento utilizado para la recolección de datos fue la aplicación de un cuestionario con preguntas popularmente conocidas como cuestiones de almanaque, siendo que, para cada cuestión, el individuo apunta su confianza en la respuesta dada. La investigación contó con una muestra de 424 individuos de las tres áreas científicas: Ciencias Exactas, Ciencias de la Vida y Humanidades, siendo 270 estudiantes de graduación y 154 profesionales ya establecidos en el mercado de trabajo. Para el análisis del exceso de confianza se utilizó el modelo formulado por Murphy (1973), cuya fórmula derivó del Brier Score. También se verificaron las relaciones en cuanto a la calibración, a través de la metodología de Lichtenstein, Fischhoff y Phillips (1982), y la agudeza, proporción de respuestas correctas. Los resultados demostraron que los profesionales de mercado son más 
excesivamente confiados que los estudiantes de graduación. Los estudiantes acertaron proporcionalmente más cuestiones en cada categoría de confianza, pero obtuvieron una menor calibración en sus juicios de probabilidad. Además, se verificó, también, la relación entre el exceso de confianza, acuidad y calibración en cuanto a la calificación de los profesionales, a la relación entre géneros femenino y masculino relacionados con las tres áreas científicas, entre edad, entre los cursos más representativos de la muestra y el grado de dificultad de las cuestiones. Palabras claves: Sobreconfianza; Profesionales; Estudiantes

\section{Introdução}

De acordo com o CPC 00 (2011), as demonstrações contábeis são elaboradas com o objetivo de fornecer informações úteis na tomada de decisões por parte dos usuários. No entanto, em muitos casos, o processo de julgamento e tomada de decisão pode ser influenciado pela irracionalidade, tanto por parte dos contadores, que elaboram as demonstrações, como por parte dos usuários, que a utilizam para suas decisões econômicas. Isso acontece porque os tomadores de decisão priorizam, na maioria das vezes, sua intuição em detrimento da racionalidade (ZINDEL, 2008).

As teorias econômicas defendem duas correntes de pensamento que tentam compreender os fatores que influenciam o processo de tomada de decisão por parte dos agentes financeiros. A primeira teoria, denominada corrente normativa, está baseada em aspectos lógico-racionais e a segunda, denominada corrente descritiva, baseia-se em aspectos comportamentais para entender a tomada de decisão (SHIMIZU, 2006).

Nas modernas teorias de finanças (corrente normativa), o investidor é racional diante das alternativas existentes, avesso ao risco e maximiza seu bem-estar utilizando a Teoria da Utilidade Esperada (TUE) (FAMA, 1970). Por outro lado, nas finanças comportamentais (corrente descritiva) o investidor é irracional e se utiliza de julgamentos intuitivos de probabilidade, empregando-se de heurísticas, para a tomada de decisões (KAHNEMAN; TVERSKY, 1974).

$\mathrm{O}$ uso de abordagens alternativas para o entendimento dos fenômenos investigados nos estudos sobre finanças comportamentais só se tornou válido porque as teorias baseadas no agente racional não explicam satisfatoriamente esses fenômenos. (YOSHINAGA; OLIVEIRA; SILVEIRA; BARROS, 2008). Segundo Milanez (2003), essa nova ciência (Finanças Comportamentais) incorpora conceitos da psicologia, da sociologia e de outras ciências como economia e contabilidade, unindo as teorias das finanças clássicas com a realidade dos mercados financeiros.

O viés cognitivo é um dos campos de estudo da psicologia cognitiva. Um dos primeiros autores a estudar sobre psicologia cognitiva foi Ulrich (1967). De acordo com este autor, a psicologia cognitiva refere-se a todo processo pelo qual o input sensório é transformado, reduzido, elaborado, armazenado, recuperado e usado pelo indivíduo.

A revolução cognitiva na psicologia criou um forte interesse na estrutura do conhecimento na memória em geral e como os indivíduos aprendem em particular. Esse paradigma de pesquisa também afeta a contabilidade e a auditoria. A aprendizagem da experiência envolve a formação e o desenvolvimento de estruturas cognitivas generalizadas que organizam o conhecimento declarativo ("saber o que" - baseado em esquemas) e o processual ("saber como" - baseado em processos) fundamentado na experiência da memória de longo prazo. (BELKAOUI, 2002).

Os psicólogos cognitivos utilizam-se de experimentos em calibração no julgamento para aprender como os indivíduos tomam decisões. Mesmo que o resultado prático dos experimentos seja limitado, os psicólogos cognitivos ainda podem oferecer uma rica compreensão de como as pessoas desenvolvem e expressam sentimentos de certeza e incerteza. (LICHTENSTEIN; FISCHHOFF; PHILLIPS, 1982). 
Para Belkaoui (2002) os nossos julgamentos ou decisões são baseados em esquemas na memória, que são desenvolvidos através de um processo gradual de abstração de conhecimento com base na experiência. $\mathrm{O}$ autor defende que, por ser a experiência o que diferencia o esquema de um indivíduo para outro, especialistas têm estruturas de conhecimento mais complexas do que estudantes, porque possuem mais experiência que estes. Assim, os esquemas de profissionais especialistas contêm mais elementos informativos do que os de estudantes, são mais organizados, contêm mais links e podem ter uma hierarquia mais complexa (BELKAOUI, 2002).

Para Ferreira e Yu (2003), quanto maior é a experiência dos agentes financeiros, maior é o seu excesso de confiança e essa confiança aumenta com o maior tempo de atuação na área. Segundo Griffin e Tversky (1992), quando a previsibilidade das situações é razoavelmente alta, os especialistas são, em geral, melhor calibrados em seus julgamentos do que os novatos. No entanto, quando a previsibilidade é muito baixa, os especialistas podem ser mais propensos ao excesso de confiança. Dessa forma, segundo os autores, o tipo de tarefa considerada é fundamental para o papel da experiência no excesso de confiança.

Nesse contexto, a presente pesquisa lança luz sobre a relação entre excesso de confiança e a qualificação. É do entendimento do pesquisador que os profissionais, cujas estruturas de memórias são mais bem estruturadas, terão uma confiança maior em seus julgamentos de probabilidade do que os estudantes, tendo em vista que, segundo Kahneman (2012), o indivíduo que possui mais conhecimento desenvolve uma ilusão acentuada de sua habilidade, tornando-se irrealisticamente superconfiante.

Alguns estudos (LICHTENSTEIN; FISCHHOFF, 1977, BELKAOUI, 2002, FERREIRA; YU, 2003) encontraram evidências de que a qualificação é uma variável significativa para o excesso de confiança e que tanto alunos como especialistas de mercado possuem esse viés cognitivo. Sendo assim, surgiu o seguinte problema: existe alguma diferença entre os dois grupos, de profissionais e de estudantes, no tocante ao excesso de confiança? Para isso, a presente pesquisa pretende estabelecer uma análise comparativa da capacidade cognitiva de julgamento entre os profissionais já estabelecidos no mercado de trabalho e os estudantes de graduação com relação ao nível de confiança em seus julgamentos de probabilidade. O objetivo da pesquisa é comparar se os profissionais são mais propensos ao viés cognitivo excesso de confiança do que os estudantes.

A justificativa deste estudo para a contabilidade decorre do fato de que conhecer e compreender os possíveis vieses cognitivos que os usuários internos e externos das informações contábeis poderão incorrer ampara o contador a julgar adequadamente e tomar melhores decisões. Esse conhecimento pode induzi-lo a preparar as demonstrações da forma mais clara possível, de acordo com a real situação econômica e financeira da empresa, de modo que a informação fique compreensível e seja recebida e processada de maneira correta, prevenindo possíveis decisões equivocadas. Segundo Kahneman e Tversky (1986), decisões certas aumentam as chances de sobrevivência em um ambiente economicamente competitivo.

No nosso dia-a-dia diversas decisões importantes são tomadas como, por exemplo, a compra de um carro, votar em determinado político, escolher uma boa escola para os filhos. Apesar de parecer decisões simples, se tomadas de maneira equivocada podem interferir significativamente a vida financeira e pessoal do indivíduo. Por isso, essa pesquisa não se limita somente aos profissionais contadores e alunos de ciências contábeis, selecionando, também, profissionais e alunos de diversas áreas como do direito (advogados, juízes e alunos de graduação em direito) e áreas ligadas a medicina (como enfermeiros, médicos e alunos de medicina).

Em muitos contextos pessoais ou profissionais o custo do julgamento errôneo pode ser trivial ou consequente (DUNNING; GRIFFIN; MILOJKOVIC, 1990). Um médico, por exemplo, ao ouvir todos os sintomas de seu paciente, utiliza-se de sua experiência para diagnosticar possíveis doenças relacionadas aos sintomas descritos. A confiança exacerbada a uma única hipótese pode levar a tratamentos errôneos. Um analista financeiro, utilizando-se de sua experiência, poderá realizar projeções de taxas de juros que aumentarão a carteira de clientes de um banco, por 
exemplo. Se a economia não se comportar conforme previsão do analista e a taxa de juros esperada não se confirmar, consequências como o aumento da inadimplência dos clientes do banco poderão ocorrer.

Dessa forma, há o entendimento do pesquisador de que o viés cognitivo excesso de confiança é de suma importância para as tomadas de decisões cotidianas. De acordo com Erceg e Galic (2014) a prevalência da confiança excessiva e as consequências perigosas que dela poderiam resultar tornam esse viés um importante objeto de pesquisa científica.

\section{Excesso de confiança}

A palavra confiança está relacionada ao grau de certeza que o indivíduo tem na validade, na exatidão ou no estado mental sobre crenças, conhecimentos, percepções, predições, julgamentos ou decisões (ZAKAY; TSAL, 1993). Para Kahneman (2012) a confiança não é apenas avaliar racionalmente a probabilidade de um julgamento estar correto ou não, confiança "é um sentimento que reflete a coerência da informação e o conforto cognitivo de processá-la".

As avaliações de probabilidade subjetiva desempenham um papel fundamental na tomada de decisões. Em muitos casos, é necessário contar com um especialista para avaliar a probabilidade de algum evento futuro. Mas quão boas são essas avaliações? Um aspecto importante da sua qualidade é chamado de calibração (LICHTENSTEIN et al., 1982). De acordo com Plous (1993) a calibração é o grau em que a confiança coincide com a precisão. Um indivíduo é perfeitamente calibrado quando a probabilidade de precisão em seus julgamentos é idêntica a probabilidade esperada de acerto.

Ressalta-se que a precisão não pode ser considerada isoladamente, ou seja, não se pode dizer que um indivíduo é bem calibrado quando ele respondeu apenas uma pergunta. A única maneira de avaliar de forma confiável a calibração é comparando a precisão e a confiança em diversos julgamentos. (LICHTENSTEIN et al., 1982).

O excesso de confiança, em sua essência, reflete o fato de que a confiança que os indivíduos têm em seus julgamentos não correspondem à exatidão real desses julgamentos (ERCEG; GALIC, 2014). Para Plous (1993) nenhum problema de julgamento e tomada de decisões é mais prevalente e potencialmente catastrófico do que o excesso de confiança. Um investidor que apresenta este viés cognitivo pode crer que detém vantagens comparativas na análise e avaliação de ativos do que outros investidores, obtendo perdas constantes. Além disso, poderá haver uma diversificação de investimentos inadequada, devido a sua crença enviesada em um único ativo, considerando que este irá gerar ganhos futuros consideráveis. (KIMURA, 2003)

Os indivíduos apresentam o excesso de confiança em suas próprias habilidades porque desconsideram a verdadeira incerteza que existe no processo (YOSHINAGA, et al., 2008) formando uma impressão forte com base em conhecimento limitado (GRIFFIN; TVERSKY, 1992). Uma vez que os investidores não são bem calibrados em seus julgamentos de probabilidade, estão propensos ao viés cognitivo excesso de confiança (ZINDEL, 2008) utilizando suas estimativas iniciais como âncoras, que são calibradas para produzir respostas finais, enviesando o processo decisório (KAHNEMAN; TVERSKY, 1974). Para Kahneman (2012) as declarações de confiança elevada informam que o indivíduo construiu uma história coerente em sua mente, não necessariamente que essa história seja verdadeira.

Griffin e Tversky (1992) questionam que os benefícios da confiança excessiva excedam seus custos. Para os autores, o excesso de confiança no diagnóstico de um paciente ou na taxa de juros projetada de um investimento qualquer pode levar a um tratamento médico inadequado e investimentos financeiros lamentáveis. "A vontade das pessoas de se envolverem em guerras seria reduzida se tivessem uma avaliação mais realista de suas chances" (GRIFFIN; TVERSKY, 1992). Para a literatura, alguns fatores têm influência para a ocorrência do viés cognitivo excesso de confiança: 
a) Questões fáceis versus questões difíceis: Kahneman e Tversky (1996) argumentam que questões fáceis não indicam excesso de confiança como com questões ligeiramente mais difíceis. Para os autores, a dificuldade é, talvez, o principal determinante, embora não o único, para o excesso de confiança.

b) Informação: De acordo com Zindel (2008) a informação é um fator que influencia na confiança de decisão do indivíduo, porque tende-se a acreditar que ela ajudará a tomar melhores decisões. No entanto, a autora alerta que muitas informações podem tornar o problema mais complexo.

c) Motivação por recompensa: A motivação pela recompensa é considerada por Bohner et al. (1998) como um dos fatores que influenciam o excesso de confiança, porque encoraja o indivíduo a abandonar o uso do esforço minimizado em favor de estratégias de estimação de probabilidade afim de obter a recompensa. Pressões sutis como impressionar o chefe ou evitar o julgamento das pessoas podem fornecer fortes incentivos para uma calibração ruim e o consequente excesso de confiança. (Lichtenstein et al., 1982)

d) Feedback: O uso do feedback após cada avaliação aumenta a condição para que as respostas após o treinamento sejam mais calibradas. No entanto, a calibração só será melhorada até uma extensão limitada que é desconhecida, ou seja, não se sabe até onde esse viés pode ser superado por meio do treinamento. (Lichtenstein et al., 1982).

e) Efeito disposição: A lógica de disposição atribui o excesso de confiança a uma característica pessoal, semelhante a um traço de personalidade. Cada indivíduo é visto como tendo uma tendência a formar expectativas altas ou baixas sobre determinadas tarefas. Quando confrontado com uma questão de conhecimento geral, essa tendência se manifesta de uma maneira que pode ser assimilada pelo seguinte raciocínio: "Eu escolhi a alternativa X. Sou geralmente uma pessoa muito competente. Portanto, há uma chance alta de que fiz a escolha correta. " Esse tipo de raciocínio implica em características afetivas para essa disposição, como a necessidade de manter um sentido reconfortante de autoestima. (YATES; LEE; SHINOTSUKA, 1996).

Um dos primeiros trabalhos sobre excesso de confiança no Brasil foi realizado por Ferreira e Yu (2003). Considerando o questionamento sobre o conceito da sobrevivência de agentes não completamente racionais dos mercados financeiros, os autores avaliaram se os profissionais de finanças cometem erros sistemáticos em suas atividades. Dessa forma, foram utilizados diversos experimentos baseados em expectativas futuras dos agentes financeiros. Com isso, os autores mostraram que profissionais experientes e atuantes no mercado financeiro possuem comportamentos excessivamente confiantes. Além disso, quanto maior era a expericnai desde profissionais, maior era o erro sistemático.

Utilizando o pressuposto de que gestores enviesados subestimam o risco de falência ou de dificuldades financeiras de suas empresas, Barros (2005) investigou se o comportamento excessivamente confiante de um gestor pode influenciar a estrutura de capital das empresas geridas por eles. $\mathrm{O}$ autor mostrou que o excesso de confiança de um executivo é positivamente relacionado a maiores tendências de alavancagem, e essa relação se torna mais significativa quando o gestor é o fundador da empresa.

Zindel (2008) analisou a relação do excesso de confiança com aspectos biológicos dos indivíduos e descobriu que a lateralidade (similaridade entre os dois lados do corpo) e a crença em Deus são duas características pessoais positivamente e significativamente relacionados a um comportamento excessivamente confiante.

Pimenta, Borsato e Ribeiro (2012) objetivaram verificar se o processo e tomada de decisão pode ser influenciado por características demográficas e pelo viés do excesso de confiança. Dentre outras características demográficas, os autores mostraram que a experiência em investimos, a quantidade de ações compradas em um determinado período, a preocupação com o retorno a médio prazo e o excesso de confiança, influenciam a tomada de decisão. 
Silva Aguiar, Araújo, Carmo, Prazeres e Soeiro (2016) analisaram se o gênero, a idade, a formação e as experiências nas decisões de investimento são fatores determinantes no excesso de confiança dos indivíduos. Com a aplicação de um questionário, os autores verificaram que a grande maioria dos respondentes (70\%) foi excessivamente confiante em suas respostas. Além disso, o trabalho evidenciou que a idade é a característica mais significativa para explicar um comportamento enviesado.

Santos, Azevedo, Assunção e Mól (2019) objetivaram verificar quais são os determinantes do excesso de confiança em estudantes de ciências contábeis. $O$ excesso de confiança foi investigado por meio de um índice, definido pelos autores como índice de Excesso de Confiança (IEC). Os resultados mostraram que a idade, o gênero, a situação matrimonial, a ocupação e o nível de salário dos discentes são determinantes que afetam o grau de excesso de confiança.

\section{Procedimentos Metodológicos}

O objetivo da pesquisa em questão é estabelecer uma análise comparativa da capacidade cognitiva de julgamento entre profissionais já estabelecidos no mercado de trabalho e alunos de graduação. Para isso foram selecionados alunos e profissionais das três áreas de conhecimento conforme definido pela Universidade de Brasília, instituição onde foi realizada a pesquisa: Humanidades, Ciências Exatas e Ciências da Vida. Os julgamentos dos profissionais de ciências exatas serão contrastados com os dos alunos desta mesma ciência, assim como em ciências da vida e humanidades, sendo a hipótese de investigação de que os profissionais já estabelecidos no mercado possuem mais excesso de confiança do que os alunos de graduação.

Tal hipótese se justifica porque a experiência é um determinante para o excesso de confiança. Sendo assim, quanto maior a experiência dos profissionais, maior é o seu excesso de confiança. Ainda, nos profissionais, esse viés é determinado pelo fato de que os esquemas de memória construídos ao longo da vida, que é subjetivo ao entendimento de cada indivíduo, não foram construídos de maneira correta. Dessa forma, mesmo dispondo de estruturas de conhecimento mais complexas, o entendimento subjetivo do fenômeno acaba enviesando o processo de julgamento (FERREIRA; YU, 2003; BELKAOUI, 2002)

O instrumento utilizado nesta pesquisa com o propósito de testar a hipótese investigada é o levantamento de dados por meio de um questionário. Inicialmente, apresentou-se uma breve explicação sobre o preenchimento do questionário. Em seguida, o instrumento foi dividido em duas partes. Na primeira parte foram coletadas as características dos respondentes, as quis o pesquisador utilizou para separar os participantes entre profissionais e estudantes, como idade, gênero, nível de instrução, curso e semestre. A segunda parte, composta por dez questões de conhecimento geral, pretende mensurar a calibração e o julgamento de confiança dos indivíduos.

Cada questão de conhecimento geral contém duas alternativas de resposta, sendo Sim ou Não para as respostas que os participantes consideraram, respectivamente, verdadeira ou falsa. Em seguida o sujeito responderá, em uma escala de meia extensão $(0,5<r t<1,0)$ a probabilidade da confiança dada em cada questão. A Figura 1 apresenta a visualização da primeira questão a ser respondida pelos participantes. Todas as demais questões seguiram o mesmo modelo.

Figura 1. Primeira questão do questionário.

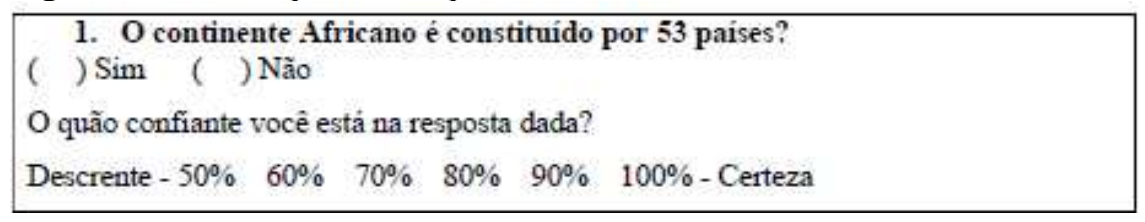

As questões foram selecionadas como de dificuldade alta tendo em vista que para a literatura questões difíceis são as que mais expressam excesso de confiança dos indivíduos 
(KAHNEMAN; TVERSKY, 1996) Isso pôde ser verificado no momento da aplicação do questionário, onde alguns indivíduos se manifestaram quanto a dificuldade das questões. O Quadro 1 apresenta as questões pertencentes ao questionário seguida das suas respectivas referências.

Quadro 1: Referências Relacionadas a Cada Questão do Questionário

\begin{tabular}{|c|c|c|c|}
\hline Questão & Referência & Questão & Referência \\
\hline $\mathbf{1}^{\mathbf{o}}$ & $\begin{array}{l}\text { O continente Africano é } \\
\text { constituído por } 53 \text { países? }\end{array}$ & $7^{\mathbf{o}}$ & O Saara é o maior deserto do mundo? Própria \\
\hline $2^{\circ}$ & $\begin{array}{l}\text { A distância entre Londres e } \\
\text { Nova York é de, } \\
\text { aproximadamente, } 5562 \mathrm{~km} ? \\
\text { (Zindel, 2008) }\end{array}$ & $\mathbf{8}^{\mathbf{o}}$ & $\begin{array}{l}\text { Em um lago, há um grupo de vitórias régias. Todos } \\
\text { os dias o grupo dobra de tamanho. Supondo que o } \\
\text { grupo leva } 100 \text { dias para cobrir o lago inteiro, então } \\
\text { para cobrir metade do lago o grupo levará } 50 \text { dias? } \\
\text { (Lucena, 2014) }\end{array}$ \\
\hline $3^{\mathbf{o}}$ & $\begin{array}{l}\text { Joanesburgo é a capital da África } \\
\text { do Sul? (Própria) }\end{array}$ & $9^{\circ}$ & $\begin{array}{l}\text { Ao lançar uma moeda para cima } 8 \text { vezes, o } \\
\text { resultado CKCKCCKK é mais provável de } \\
\text { acontecer que KKKKKKKK? (onde, } \mathrm{C}=\text { cara e K } \\
=\text { coroa (Lucena, 2014) }\end{array}$ \\
\hline $4^{\circ}$ & $\begin{array}{l}\text { Os Estados Unidos iniciaram a } \\
\text { construção do Canal do Panamá? } \\
\text { (Própria) }\end{array}$ & $10^{\circ}$ & $\begin{array}{l}\text { Tens } 1000 \text {, acrescenta-lhe } 40 \text {. Acrescenta mais } 100 \\
\text { Acrescenta mais } 30 \text { e novamente } 1000 \text {. Acrescenta } \\
\text { 20. Acrescenta } 1000 \text { e ainda } 10 . \text { O total da soma de } \\
\text { 5000? Em } \\
\text { http://patriciafabiano.blogspot.com.br/2010/02/teste } \\
\text { seu-cerebro.html, acessado em } 05 / 04 / 2017 \text {. }\end{array}$ \\
\hline $5^{\circ}$ & $\begin{array}{l}\text { A Itália possui uma extensão } \\
\text { territorial de } 50.000 \mathrm{~km}^{2} ? \\
\text { (Zindel, 2008) }\end{array}$ & $11^{\mathbf{o}}$ & $\begin{array}{l}\text { Um menino pagou } \mathrm{R} \$ 11,00 \text { reais por uma } \\
\text { embalagem com tampa. A embalagem custa } 10 \text { reai } \\
\text { a mais que a tampa. Logo, a tampa custa } \\
\mathrm{R} \$ 1,00 \text { real? (Adaptado de Lucena }(2014) \text { ) }\end{array}$ \\
\hline $6^{\mathbf{0}}$ & $\begin{array}{l}\text { A idade média foi um período } \\
\text { histórico da Europa entre os } \\
\text { séculos V e XV? (Própria) }\end{array}$ & -- & --- \\
\hline
\end{tabular}

Fonte: Dados da pesquisa

A coleta de dados da presente pesquisa foi realizada entre os dias 27 de abril de 2017 e 23 de maio de 2017. Foram coletados no total uma amostra de 270 estudantes e 154 profissionais de mercado, totalizando 424 sujeitos.

A coleta de dados com o questionário físico para os alunos ocorreu dentro da Universidade de Brasília. Os alunos foram abordados em sala de aula e, após uma explicação sobre a pesquisa, foram solicitados a responderem da maneira mais verdadeira possível todas as questões.

A coleta de dados também se realizou via Internet, com um formulário online. O link com o questionário foi enviado para grupos de alunos da Universidade de Brasília nas redes sociais, para conselhos federais e diretamente para correios eletrônicos de alunos e profissionais. Com relação aos profissionais de mercado a grande maioria das respostas foram coletadas via questionário online.

A metodologia utilizada na pesquisa para fornecer informação sobre a calibração do julgamento é a metodologia de calibração de Lichtenstein et al., (1982), cuja fórmula derivou do Brier Score (1950).

$$
C=\frac{1}{N} \sum_{t=1}^{T} n_{t}\left(r_{t}-c_{t}\right)^{2}
$$

Onde:

- $C=$ Variância das proporções corretas $c_{t}$; 
- $r_{t}=$ Graus correspondentes de confiança para a categoria $t$

- $n_{t}=$ Número de respostas na categoria de confiança $t$;

- $T$ = Número total de categorias de respostas usadas;

- $N$ = Número total de respostas;

- $c_{t}=$ Proporção correta para todos os itens assinalados com a probabilidade $r_{t}$.

Para todas as variações de probabilidade, a calibração pode ser relatada por meio de uma curva de calibração. Tal curva é derivada da seguinte maneira: i) coletar muitas avaliações de probabilidade (questionário); ii) agrupar as categorias semelhantes, por exemplo, 70\%; iii) dentro de cada categoria, calcule a proporção de respostas corretas; iv) para cada categoria, trace a resposta média (na abscissa) contra a proporção correta (em ordenadas). A calibração perfeita seria mostrada por todos os pontos que caem na linha de identidade (LICHTENSTEIN et al., 1982).

Para mensurar o excesso de confiança foi utilizada a metodologia formulada por Murphy (1973), também derivada do Brier Score, que dispõe de um sinal positivo para indicar se a pessoa é excessivamente confiante e de um sinal negativo para demonstrar uma baixa confiança do indivíduo, conforme Fórmula 3.2 abaixo.

$$
\text { Excesso } / \text { Falta de Confiança }=\frac{1}{N} \sum_{t=1}^{T} n_{t}\left(r_{t}-c_{t}\right)
$$

Onde,

- $r_{t}=$ graus correspondentes de confiança para categoria $t$;

- $n_{t}=$ número de respostas na categoria de confiança;

- $T$ = número total de categorias de respostas usadas;

- $N$ = número total de respostas;

- $c_{t}=$ proporção correta para todos os itens assinalados com a probabilidade $r_{t}$.

Assim como há muitas maneiras de mediar a confiança, também existem várias técnicas para avaliar a calibração. Uma maneira simples de medir a calibração no julgamento é calcular a diferença entre os índices de confiança médio e a proporção global de julgamentos precisos. Por exemplo, um indivíduo que tem um índice médio de confiança de $80 \%$ em um conjunto de itens de conhecimento geral, mas só está certo em apenas $60 \%$ dos itens. Esse indivíduo é confiante demais em 20\%. Murphy (1973) chama a atenção, no entanto, que essa medida de julgamento, em alguns casos, pode ser enganosa. Um sujeito que possua precisão geral e confiança de $80 \%$, pode não ser perfeitamente calibrada. Isso porque, se metade das questões o indivíduo marcou $60 \%$ de confiança e a outra metade foi marcada com $100 \%$ de confiança, com um resultado médio de $80 \%$ de confiança geral das questões, ele seria menos confiável quando selecionasse a questão que foi marcada com $60 \%$ de certeza e teria excesso de confiança quando da questão marcada com $100 \%$ de certeza (PLOUS, 1993).

Outra medida de calibração é o "índice surpresa". Esse índice é usado para os casos em que a porcentagem de julgamentos se encontra além dos limites de um intervalo de confiança desconhecido (PLOUS, 1993). Por exemplo, suponha que um sujeito estimou em $90 \%$ a confiança de a distância entre Nova York e Londres ser entre um intervalo de 6 mil quilômetros e 7 mil quilômetros. Como a resposta correta é menor do que esse intervalo, essa resposta seria marcada como uma surpresa.

Além do cálculo dos valores médios, outras estatísticas descritivas foram calculadas. Também foram realizados vários testes estatísticos, em especial o teste de duas médias, sendo usado 5\% como parâmetro de decisão. Optou-se por apresentar estas estatísticas somente quando representassem um ganho em termos da argumentação e comprovação dos resultados. No caso do teste de duas médias, apresenta-se, quando for o caso, o p-valor. 


\section{Resultados}

\subsection{Análise do perfil da amostra}

Participaram da pesquisa 424 sujeitos dos quais 270 eram estudantes de graduação de 22 cursos diferentes e 154 eram profissionais de mercado. Dos estudantes, 82 eram de cursos classificados como de Ciências Exatas, 95 de Ciências da Vida e 93 de Humanidades. Para os profissionais, foram 45 da área de Ciências Exatas, 44 de Ciências da Vida e 65 de Humanidades.

Com relação ao gênero, no total 261 indivíduos eram do gênero masculino e 163 do feminino. No caso dos estudantes, participaram da pesquisa 106 alunos do gênero feminino, sendo 16 de Ciências Exatas, 49 de Ciências da Vida e 41 de Humanidades. Dos estudantes do gênero masculino, 63 eram Ciências Exatas, 46 de Ciências da Vida e 52 de Humanidades. Quanto aos profissionais, 54 eram do gênero feminino, sendo 6 de Ciências Exatas, 25 de Ciências da Vida e 23 de Humanidades, e 100 profissionais do gênero masculino, sendo 49 de Ciências Exatas, 19 de Ciências da Vida e 42 de Humanidades.

A média da idade dos 270 estudantes foi de 20,88, sendo o desvio padrão 3,21 , e dos profissionais foi de 36,71 , com desvio padrão de 10,86, indicando uma idade média diferente entre os dois grupos ( $\mathrm{p}$-valor $=0,0000)$. A idade mínima e máxima, respectivamente, dos estudantes foram 17 e 42 anos e dos profissionais 22 e 63 anos. Com relação a qualificação dos profissionais, participaram da pesquisa 61 profissionais que possuíam graduação, 60 que possuíam especialização, 26 que possuíam mestrado, 5 com doutorado e 2 com pós-doutorado.

\subsection{Análise dos resultados obtidos}

Neste tópico são analisadas as calibrações de alunos e profissionais por área científica de acordo com a curva de calibração (gráficos 1, 2 e 3). No eixo das ordenadas encontram-se a proporção de respostas corretas $(c t)$ e no eixo das abcissas os níveis de confiança $(r t)$ selecionados em cada questão. A linha de identidade equivale a calibração perfeita, ou seja, para uma confiança de $60 \%$ uma precisão de respostas corretas correspondente a $60 \%$, para uma confiança de $80 \%$, uma precisão de $80 \%$, e assim por diante.

Para as tarefas de meia extensão $(0,5<r t<1,0)$, as avaliações mal calibradas podem ser excessivamente confiantes, de modo que as proporções corretas são menores do que as probabilidades avaliadas, fazendo com que a curva de calibração fique abaixo da linha de identidade. Ao contrário, para o caso de baixa confiança, onde as proporções corretas são maiores que as probabilidades avaliadas, a curva de calibração situa-se acima da linha de identidade (LICHTENSTEIN et al., 1982).

Gráfico 1 - Curva de Calibração no Julgamento de Alunos e Profissionais na Área de Ciências Exatas

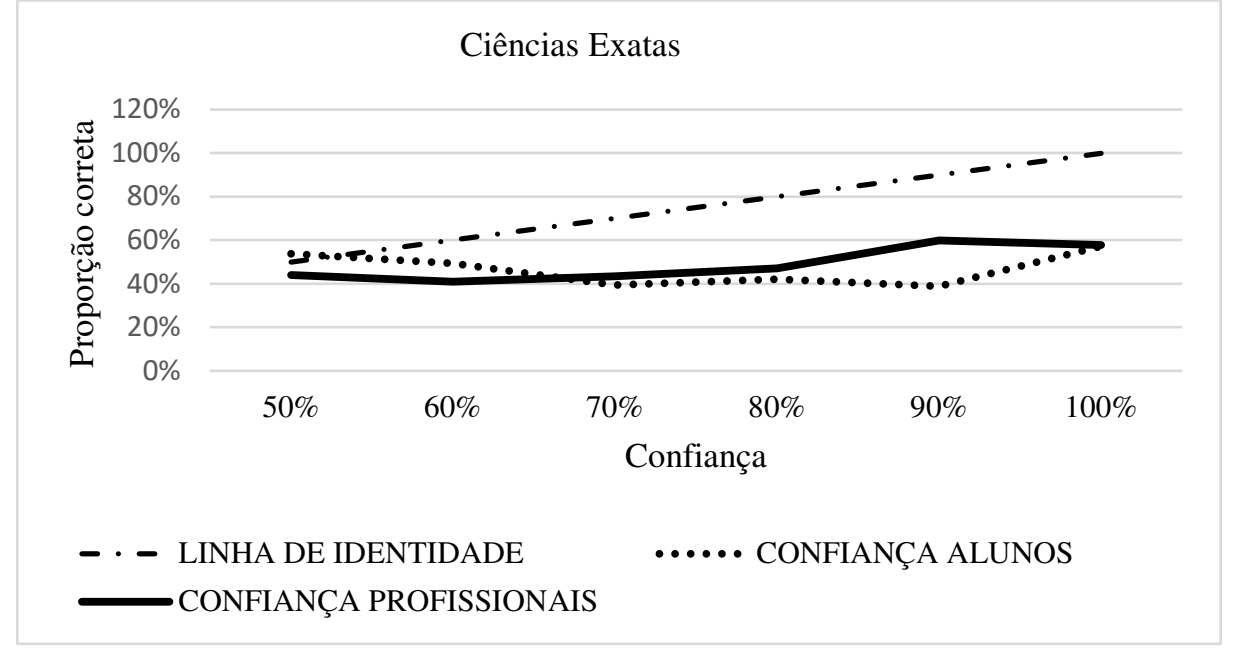

Fonte: Dados da pesquisa 
Da análise do gráfico 1, pode-se inferir que:

- Os alunos estavam efetivamente corretos $53,77 \%$ das vezes em que a alternativa de confiança escolhida foi 50\%. Enquanto que os profissionais estavam de fato corretos $44 \%$ das vezes;

- Os alunos estavam efetivamente corretos $49,31 \%$ das vezes em que a alternativa escolhida foi $60 \%$. Enquanto que os profissionais estavam de fato corretos $41,01 \%$ das vezes;

- Os alunos estavam efetivamente corretos $39,45 \%$ das vezes em que a alternativa escolhida foi $70 \%$. Enquanto que os profissionais estavam de fato corretos $43,48 \%$ das vezes;

- Os alunos estavam efetivamente corretos $42,09 \%$ das vezes em que a alternativa escolhida foi $80 \%$. Enquanto que os profissionais estavam de fato corretos $47,12 \%$ das vezes;

- Os alunos estavam efetivamente corretos $38,81 \%$ das vezes em que a alternativa escolhida foi $90 \%$. Enquanto que os profissionais estavam de fato corretos $59,95 \%$ das vezes;

- Os alunos estavam efetivamente corretos $57,29 \%$ das vezes em que a alternativa escolhida foi $100 \%$. Enquanto que os profissionais estavam de fato corretos $57,80 \%$ das vezes.

Gráfico 2 - Curva de Calibração no Julgamento de Alunos e Profissionais na Área de Ciências da Vida

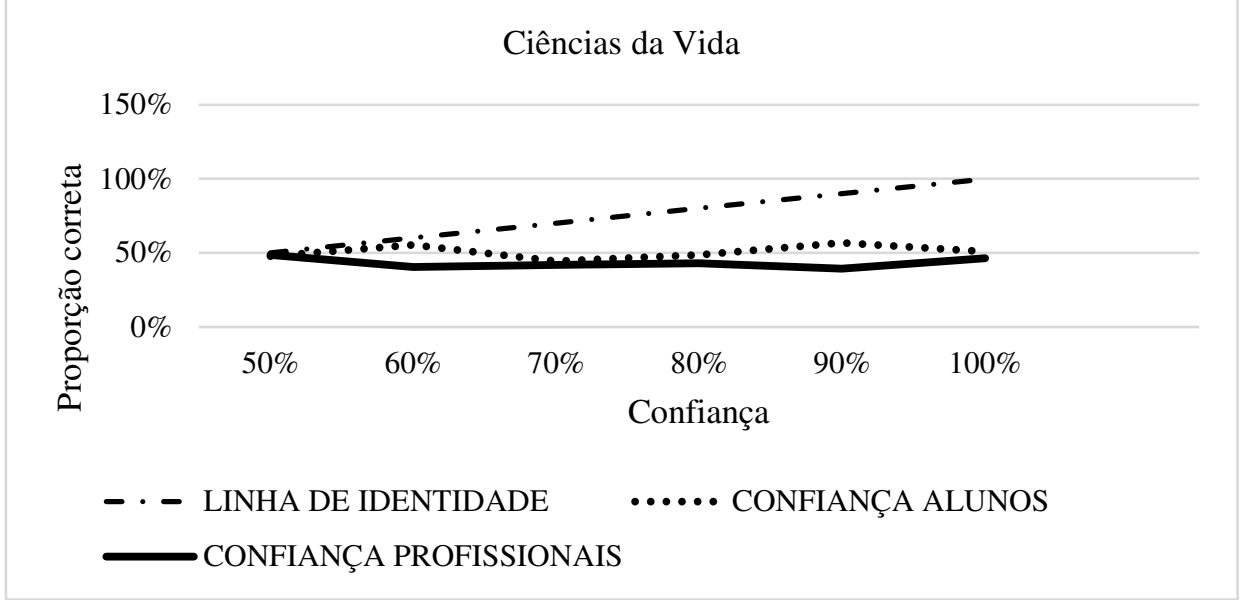

Fonte: Dados da pesquisa

Da análise do gráfico 2, pode-se inferir que:

- Os alunos estavam efetivamente corretos $47,75 \%$ das vezes em que a alternativa de confiança escolhida foi $50 \%$. Enquanto que os profissionais estavam de fato corretos $48,69 \%$ das vezes;

- Os alunos estavam efetivamente corretos $55,31 \%$ das vezes em que a alternativa escolhida foi $60 \%$. Enquanto que os profissionais estavam de fato corretos $40,47 \%$ das vezes;

- Os alunos estavam efetivamente corretos $44,39 \%$ das vezes em que a alternativa escolhida foi $70 \%$. Enquanto que os profissionais estavam de fato corretos $41,67 \%$ das vezes;

- Os alunos estavam efetivamente corretos $48,56 \%$ das vezes em que a alternativa escolhida foi $80 \%$. Enquanto que os profissionais estavam de fato corretos $42,93 \%$ das vezes;

- Os alunos estavam efetivamente corretos $56,71 \%$ das vezes em que a alternativa escolhida foi $90 \%$. Enquanto que os profissionais estavam de fato corretos $39,39 \%$ das vezes;

- Os alunos estavam efetivamente corretos $50,65 \%$ das vezes em que a alternativa escolhida foi $100 \%$. Enquanto que os profissionais estavam de fato corretos $46,16 \%$ das vezes. 
Gráfico 3 - Curva de Calibração no Julgamento de Alunos e Profissionais na Área de Humanidades

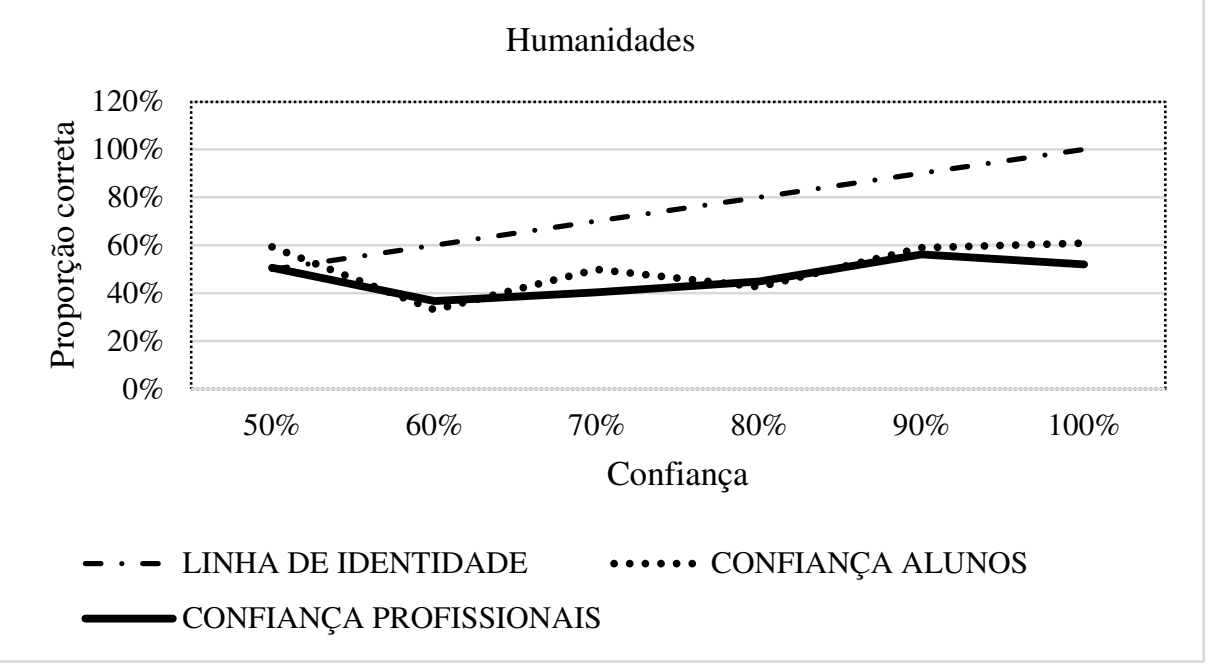

Fonte: Dados da pesquisa

Da análise do gráfico 3, pode-se inferir que:

- Os alunos estavam efetivamente corretos $59,33 \%$ das vezes em que a alternativa de confiança escolhida foi $50 \%$. Enquanto que os profissionais estavam de fato corretos $50,58 \%$ das vezes;

- Os alunos estavam efetivamente corretos $33,04 \%$ das vezes em que a alternativa escolhida foi $60 \%$. Enquanto que os profissionais estavam de fato corretos $36,71 \%$ das vezes;

- Os alunos estavam efetivamente corretos $49,80 \%$ das vezes em que a alternativa escolhida foi $70 \%$. Enquanto que os profissionais estavam de fato corretos $40,25 \%$ das vezes;

- Os alunos estavam efetivamente corretos $42,60 \%$ das vezes em que a alternativa escolhida foi $80 \%$. Enquanto que os profissionais estavam de fato corretos $44,76 \%$ das vezes;

- Os alunos estavam efetivamente corretos $58,94 \%$ das vezes em que a alternativa escolhida foi $90 \%$. Enquanto que os profissionais estavam de fato corretos $56,16 \%$ das vezes;

- Os alunos estavam efetivamente corretos $60,90 \%$ das vezes em que a alternativa escolhida foi $100 \%$. Enquanto que os profissionais estavam de fato corretos $51,97 \%$ das vezes.

De acordo com os resultados apresentados anteriormente pode-se afirmar que a grande maioria dos sujeitos que participaram da presente pesquisa foram excessivamente confiantes em seus julgamentos de probabilidade e essa confiança aumentou a medida que o nível de confiança foi maior. Analisando-se os gráficos, é possível perceber também que as linhas de calibração dos sujeitos, tanto profissionais quanto estudantes, não crescem no mesmo ritmo que a linha de identidade. Tal fato sugere que o excesso de confiança é maior quando o nível de confiança é maior. Essa situação corrobora os achados em Zindel (2008).

De acordo com os resultados, constatou-se que em três momentos houveram baixa confiança dos sujeitos: na categoria de 50\% para alunos de Ciências Exatas e Humanidades e profissionais de Humanidades. Tal fato foi ser constatado pela Fórmula 3.2, onde os percentuais foram negativos para os três casos: - 7,35\%, - 20,17\% e - 1,28\%, respectivamente.

A Tabela 1 apresenta dados referentes a média e desvio padrão relacionados a calibração, acuidade e excesso de confiança dos alunos e profissionais, respectivamente. 
Tabela 1: Média e Desvio Padrão Relacionados a Calibração, Acuidade e Excesso de Confiança de Profissionais e Alunos por Área Científica

\begin{tabular}{|c|c|c|c|c|}
\hline & MEDIDA & AREA CIENTÍFICA & $\begin{array}{l}\text { MÉDIA } \\
(\%)\end{array}$ & $\begin{array}{l}\text { DESVIO PADRÃO } \\
(\%)\end{array}$ \\
\hline \multirow{9}{*}{ 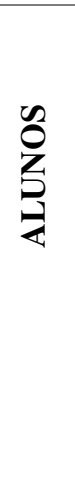 } & \multirow{3}{*}{$\begin{array}{c}\text { Calibração (Lichtenstein et al. } \\
\text { 1982) }\end{array}$} & Ciências Exatas & 38,18 & 37,02 \\
\hline & & Ciências da Vida & 29,35 & 34,67 \\
\hline & & Humanidades & 26,61 & 26,57 \\
\hline & \multirow{3}{*}{$\begin{array}{l}\text { Acuidade (Proporção de } \\
\text { respostas corretas) }\end{array}$} & Ciências Exatas & 46,78 & 7,81 \\
\hline & & Ciências da Vida & 50,56 & 4,70 \\
\hline & & Humanidades & 50,77 & 11,17 \\
\hline & \multirow{3}{*}{$\begin{array}{l}\text { Excesso de confiança (Murphy, } \\
\text { 1973) }\end{array}$} & Ciências Exatas & 55,46 & 64,86 \\
\hline & & Ciências da Vida & 50,21 & 59,37 \\
\hline & & Humanidades & 44,41 & 51,37 \\
\hline \multirow{9}{*}{ 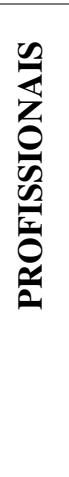 } & \multirow{3}{*}{$\begin{array}{c}\text { Calibração (Lichtenstein et al. } \\
\text { 1982) }\end{array}$} & Ciências Exatas & 32,97 & 35,82 \\
\hline & & Ciências da Vida & 39,24 & 38,93 \\
\hline & & Humanidades & 33,12 & 36,71 \\
\hline & \multirow{3}{*}{$\begin{array}{l}\text { Acuidade (Proporção de } \\
\text { respostas corretas) }\end{array}$} & Ciências Exatas & 48,89 & 8,00 \\
\hline & & Ciências da Vida & 43,22 & 3,56 \\
\hline & & Humanidades & 46,74 & 7,45 \\
\hline & \multirow{3}{*}{$\begin{array}{l}\text { Excesso de confiança (Murphy, } \\
\text { 1973) }\end{array}$} & Ciências Exatas & 55,86 & 69,52 \\
\hline & & Ciências da Vida & 60,34 & 56,22 \\
\hline & & Humanidades & 55,26 & 64,36 \\
\hline
\end{tabular}

Fonte: Dados da pesquisa

Para a área científica de Ciências Exatas encontrou-se uma acuidade média de 46,78\%, com desvio padrão de $7,81 \%$, para os alunos e $48,89 \%$, com desvio padrão de $8 \%$, para os profissionais, o que sugere que os profissionais obtiveram uma maior proporção de respostas corretas, embora sem diferença estatística ( $\mathrm{p}$-valor $=0,1513$ ). No entanto, os alunos mostraram-se mais bem calibrados, $38,18 \%$, com desvio padrão de $37,02 \%$, do que os profissionais, 32,97\%, com desvio padrão de $35,82 \%$, mas também sem diferença estatística entre esses valores (p-valor $=0,4444)$. Ou seja, as estimativas de confiança coincidiram com os resultados corretos 5,21\% a mais nos alunos do que nos profissionais.

Para a área científica de Ciências da Vida encontrou-se uma acuidade média para os alunos de $50,56 \%$, com desvio padrão de $4,7 \%$, e para os profissionais de $43,22 \%$, com desvio padrão de $3,56 \%$, estatisticamente diferente ( $\mathrm{p}$-valor $=0,0000$ ). Neste caso, ao contrário do exposto acima, as estimativas de respostas corretas para os alunos foi 7,34\% maior do que para os profissionais. Entretanto, a média de calibração dos alunos foi $9,89 \%$ menor do que a calibração dos profissionais; o resultado do teste de duas médias mostrou que as médias são diferentes ( $\mathrm{p}$-valor $=$ 0,0047).

Para a área científica de Humanidades, encontrou-se uma acuidade média de 50,77\%, com desvio padrão de $11,17 \%$, para os alunos e de $46,74 \%$, com desvio padrão de $7,45 \%$, para os profissionais. Dessa forma, a proporção de respostas corretas foi 4,03\% maior para os alunos (pvalor de 0,0121 ). No caso da calibração, os alunos foram em média $26,61 \%$ calibrados em seus julgamentos, com desvio padrão de $26,57 \%$, e os profissionais $33,12 \%$, com desvio padrão de $36,71 \%$ (p-valor $=0,1978$ ). Como ocorreu em Ciências da Vida, os profissionais de Humanidades também acertaram proporcionalmente menos, mas foram melhor calibrados em seus julgamentos em cada categoria de confiança. 
No geral os profissionais obtiveram uma acuidade média de $46,28 \%$ e os estudantes de 49,37\%. Sendo assim, os alunos acertaram proporcionalmente $3,09 \%$ a mais das questões (p-valor $=0,0219$ ). Porém, a calibração dos profissionais foi 3,73\% maior que a dos alunos, que foi de $31,38 \%$, muito embora esses resultados não sejam estatisticamente significativos ( $\mathrm{p}$-valor $=$ 0,53,81). Associando estes resultados com os achados de Lichtenstein et al., 1982 e de Freitas (2006), que afirmam que os indivíduos são mal calibrados e que essa característica está intrinsicamente relacionada a um comportamento excessivamente, evidencia-se que, no geral, os profissionais foram mais excessivamente confiantes em relação aos estudantes.

A média de excesso de confiança, baseado no Escore Brier, dos alunos de Ciências Exatas foi de $55,46 \%$, ou seja, em média 55,46\% das estimativas de respostas corretas foram maiores do que a acuidade propriamente dita. Assim, as proporções corretas foram menores do que a média do grau de confiança. Para os profissionais de Ciências Exatas, a média de excesso de confiança foi de 55,86\%. Dessa forma, na comparação entre esses dois grupos, a média de excesso de confiança foram muito próximas. Com relação a área científica de Ciências da Vida, os alunos apresentaram uma média de excesso de confiança de 50,21\%, com desvio padrão de $59,37 \%$, e os profissionais uma média de $60,34 \%$, com desvio padrão de $56,22 \%$. Ou seja, os profissionais da área de Ciências da Vida foram excessivamente confiantes $10,13 \%$ a mais em relação aos alunos. No que se refere a área científica de Humanidades os alunos apresentaram um excesso de confiança de $44,41 \%$, com desvio padrão de $51,37 \%$, e os profissionais de mercado $55,26 \%$, com desvio padrão de $64,36 \%$. Assim, os profissionais apresentaram $10,85 \%$ a mais de excesso de confiança e relação aos alunos. Esses resultados corroboram os achados de Ferreira e Yu (2003) e Lima Filho, Bruni e Sampaio (2012), que mostraram que os profissionais são mais excessivamente confiantes do que os estudantes e refuta as evidencias de Silva Aguiar et al (2016), onde os autores não encontraram um resultados positivo entre a experiência e o excesso de confiança.

Além disso, de acordo com os dados apresentados, no geral, os dois grupos, estudantes e profissionais, foram excessivamente confiantes. Esses dados são compatíveis com Lichtenstein $e t$ $a l .$, (1982) que afirmam que o excesso de confiança é encontrado na maioria das tarefas.

Tabela 2: Média da Acuidade, Calibração e Excesso de Confiança dos Profissionais por Qualificação.

\begin{tabular}{ccccc}
$\begin{array}{c}\text { Qualificação dos } \\
\text { profissionais }\end{array}$ & $\boldsymbol{N}$ & $\begin{array}{c}\text { Acuidade (Proporção } \\
\text { de respostas corretas) }\end{array}$ & $\begin{array}{c}\text { Calibração } \\
\text { (Lichtenstein et al. } \\
\text { 1982) }\end{array}$ & $\begin{array}{c}\text { Excesso de confiança } \\
\text { (Murphy, 1973) }\end{array}$ \\
\hline Graduação & 649 & $41,45 \%$ & $36,30 \%$ & $61,14 \%$ \\
\hline Especialização & 660 & $49,55 \%$ & $35,74 \%$ & $54,80 \%$ \\
\hline Mestrado & 286 & $49,26 \%$ & $33,63 \%$ & $48,16 \%$ \\
\hline Doutorado & 55 & $32,57 \%$ & $72,44 \%$ & $78,43 \%$ \\
\hline Pós-Doutorado & 22 & $22,73 \%$ & $70,00 \%$ & $76,00 \%$ \\
\hline
\end{tabular}

Fonte: Dados da pesquisa

O $n t$ encontrado para os profissionais que possuíam graduação foi, respectivamente, 107 , 99, 130, 63, 51 e 199. Para os profissionais que possuíam especialização o $n t$ foi de 108, 72, 101, 75,52 e 252, respectivamente. O $n t$ dos profissionais com mestrado foi de 60, 27, 40, 16,35 e 108, respectivamente. Já para os profissionais com doutorado foi de 4, 5, 13, 3, 15 e 15, respectivamente, e para os profissionais com pós-doutorado, o $n t$ encontrado foi de 2, 5, 1, 2, 1 e 11 , respectivamente.

No que se refere a qualificação dos profissionais, os que possuem especialização apresentaram maior acuidade média em suas respostas, 49,55\%, ao contrário dos profissionais que possuem pós-doutorado, que apresentaram uma acuidade média de $22,73 \%$. Com relação a variável calibração, as estimativas médias de confiança dos profissionais que possuem doutorado foram as que mais coincidiram com os resultados corretos, $72,44 \%$, ao contrário dos profissionais que possuem mestrado, que obtiveram uma calibração média de apenas 33,63\%. No tocante ao 
excesso de confiança os profissionais que possuem doutorado foram os que mais apresentaram esse viés, $78,43 \%$, ou seja, em média 78,43\% das estimativas de respostas corretas foram maiores do que a acuidade propriamente dita. Os profissionais que possuem mestrado foram os que menos apresentaram esse viés, sendo suas estimativas de respostas corretas $48,16 \%$ acima da proporção de respostas corretas de fato.

Vale ressaltar que na categoria de $50 \%$ para os profissionais que possuem especialização houve baixa confiança no julgamento. Tal fato se revela pelo resultado negativo, - 18,94\%, utilizando-se a Fórmula 3.2.

Tais resultados não se identificam com os achados em Ferreira e Yu (2003), que mostraram que quanto maior é a experiência dos agentes, maior é o seu excesso de confiança. Isso porque, de acordo com a Tabela 2, não houve um crescimento constante do grau de excesso de confiança relacionado ao aumento da qualificação dos profissionais. Os grandes níveis de excesso de confiança, principalmente para os profissionais com qualificação em Doutorado e Pós-Doutorado, estão de acordo com os achados de Sampaio et al (2012), que encontraram valores estatisticamente significantes para o excesso de confiança em alunos de pós-graduação.

Tabela 3: Média da Acuidade, Calibração e Excesso de Confiança dos Alunos e Profissionais do Gênero Feminino

\begin{tabular}{cccccc}
\hline \multirow{2}{*}{ Gênero feminino } & $\boldsymbol{N}$ & $\begin{array}{c}\text { Acuidade } \\
\text { (Proporção de } \\
\text { respostas corretas) }\end{array}$ & $\begin{array}{c}\text { Calibração } \\
\text { (Lichtenstein et } \\
\text { al. 1982) }\end{array}$ & $\begin{array}{c}\text { Excesso de } \\
\text { confiança } \\
\text { (Murphy, 1973) }\end{array}$ \\
\hline \multirow{2}{*}{ ALUNOS } & Ciências Exatas & 209 & $33,87 \%$ & $60,16 \%$ & $73,60 \%$ \\
\cline { 2 - 6 } & Ciências da Vida & 539 & $49,02 \%$ & $29,43 \%$ & $48,82 \%$ \\
\cline { 2 - 6 } & Humanidades & 451 & $45,14 \%$ & $34,18 \%$ & $50,00 \%$ \\
\hline \multirow{2}{*}{ PROFISSIONAIS } & Ciências Exatas & 66 & $26,66 \%$ & $67,03 \%$ & $76,41 \%$ \\
\cline { 2 - 6 } & Ciências da Vida & 275 & $38,12 \%$ & $49,02 \%$ & $57,93 \%$ \\
\cline { 2 - 6 } & Humanidades & 253 & $36,53 \%$ & $52,27 \%$ & $67,30 \%$ \\
\hline
\end{tabular}

Fonte: Dados da pesquisa

No que se refere a relação entre a média de acuidade, calibração e excesso de confiança de alunos e profissionais do gênero feminino, conforme Tabela 3, conclui-se que, para a variável acuidade média, as alunas de Ciências da Vida ( $n t$ igual a 132, 60, 78, 60, 66 e 143, respetivamente) foram as que proporcionalmente acertaram mais, $49,02 \%$, enquanto que as profissionais de Ciências Exatas ( $n t$ igual a 17, 11, 15, 6, 6, e 11, respectivamente) foram as que proporcionalmente acertaram menos, acuidade de $26,66 \%$. Em relação a calibração média, as estimativas de confiança das profissionais de Ciências da Exatas coincidiram 67,03\% com as respostas corretas, enquanto que as estudantes de Ciências da Vida coincidiram 29,43\%, sendo, respectivamente, a maior e a menor proporção para essa variável. No tocante ao excesso de confiança médio, a área de Ciências Exatas foi a que mais chamou a atenção tendo em vista que as estudantes ( $n t$ igual a 43, 31, 41, 21,18 e 55, respectivamente) e profissionais (nt igual a 17, $11,15,6,6$ e 11, respectivamente) tiveram, nessa ordem, 73,60\% e 76,41\% das suas estimas de respostas corretas maiores que a acuidade propriamente dita.

Houve baixa confiança na categoria de $50 \%$ para estudantes gênero feminino na área de Humanidades, $-7,2 \%$, com $n t$ igual a 103, 48, 80, 46, 57 e 117, respectivamente, e para profissionais também do gênero feminino na área de Ciências da Vida, - 3,95\%, com $n t$ igual a 68, 47, 59, 31, 22 e 48, respectivamente.

Para os participantes da pesquisa do gênero masculino, os alunos da área científica de Humanidades ( $n t$ igual a 98, 65, 80, 62, 56 e 211, nessa ordem) apresentaram o maior grau de acuidade média, 54,76\%, enquanto que os profissionais de Ciências da Vida ( $n t$ igual a 11, 28, 30, 28, 23 e 89, respectivamente) apresentaram o menor, 46,10\%. No caso da calibração média, verificou-se que a calibração dos estudantes de Ciências da Exatas ( $n t$ igual a 117, 58, 70, 78, 78 
e 285 , respectivamente) foi significativa em relação aos demais, sendo $72,11 \%$ das vezes que suas estimativas de confiança coincidiram com os resultados corretos. Em segundo lugar estão os profissionais de Ciências da Vida, que obtiveram um grau de calibração médio de 48,95\%. Estes profissionais ainda foram os que obtiveram o maior excesso de confiança médio, $59,78 \%$.

Tabela 4: Média da Acuidade, Calibração e Excesso de Confiança dos Alunos e Profissionais do Gênero Masculino

\begin{tabular}{cccccc} 
Gênero masculino & $\boldsymbol{N}$ & $\begin{array}{c}\text { Acuidade } \\
\text { (Proporção de } \\
\text { respostas } \\
\text { corretas) }\end{array}$ & $\begin{array}{c}\text { Calibração } \\
\text { (Lichtenstein et } \\
\text { al. 1982) }\end{array}$ & $\begin{array}{c}\text { Excesso de } \\
\text { confiança } \\
\text { (Murphy, 1973) }\end{array}$ \\
\hline \multirow{2}{*}{ ALUNOS } & Ciências Exatas & 686 & $53,57 \%$ & $72,11 \%$ & $49,10 \%$ \\
\cline { 2 - 6 } & Ciências da Vida & 506 & $53,40 \%$ & $36,28 \%$ & $48,29 \%$ \\
\hline \multirow{2}{*}{ PROFISSIONAIS } & Humanidades & 572 & $54,76 \%$ & $29,41 \%$ & $40,07 \%$ \\
\cline { 2 - 6 } & Ciências Exatas & 363 & $46,10 \%$ & $36,75 \%$ & $59,78 \%$ \\
\cline { 2 - 6 } & Ciências da Vida & 209 & $44,03 \%$ & $48,95 \%$ & $64,00 \%$ \\
\hline
\end{tabular}

Fonte: Dados da pesquisa

No que concerne a relação entre gênero feminino e masculino, verificou-se que a proporção média de respostas corretas do gênero feminino, $38,22 \%$, foi menor do que a proporção do gênero masculino, 50,38\%, ou seja, as participantes da pesquisa foram menos acuradas que os participantes. Em relação a calibração, o gênero feminino também obteve um percentual menor do que o gênero masculino, sendo $48,68 \%$ e $42,93 \%$ a calibração média, nessa ordem. No que diz respeito a média de excesso de confiança, a diferença entre o gênero feminino e masculino foi significativa. Em média $62,34 \%$ das estimativas das participantes foram maiores que a acuidade, enquanto que em média, as estimativas dos participantes do gênero masculino foram 50,54\% maiores que a proporção de respostas corretas. Tal resultado é incompatível com o achado em Barber e Odean (2001), Zindel (2008) e Lima Filho, Bruni e Sampaio (2012), Santos et al (2019), onde os indivíduos do gênero masculino foram excessivamente mais confiantes do que os do gênero feminino. Por outro lado, Silva Aguiar et al (2016) não encontraram relação significativa entre gênero e excesso de confiança.

Apurou-se, também, a relação entre a idade dos participantes para aferir se esta variável é relevante na análise do viés cognitivo excesso de confiança. Para isso, os participantes foram divididos em dois grupos. Os 286 indivíduos do primeiro grupo possuem idades entre 17 e 24 anos com $N$ igual a 2929 e $n t$ igual a 557, 322, 403, 322, 346 e 976, respectivamente, e os 157 indivíduos do segundo grupo, entre 25 e 63 anos, com $N$ igual a 1727 e $n t$ igual a 298, 203, 299, 167, 163 e 597, respectivamente. Com relação a proporção média de respostas corretas, o primeiro grupo apresentou uma acuidade média $0,25 \%$ maior que o segundo grupo, sendo assim, não foi verificado uma diferença significativa entre os grupos.

O primeiro grupo apresentou uma calibração de $29,41 \%$ enquanto que o segundo grupo apresentou uma calibração de $30,59 \%$. Para o excesso de confiança foi encontrado um índice de $53,63 \%$ para os indivíduos do primeiro grupo, com baixa confiança $(-1,58 \%)$ na categoria de $50 \%$, e $55,13 \%$ para a segunda categoria, também apresentando uma baixa confiança $(-1,16 \%)$ na categoria de $50 \%$. Sendo assim, verificou-se que os sujeitos mais novos foram menos calibrados em seus julgamentos de probabilidade e mas obtiveram um excesso de confiança médio menor do que os com idades superiores. Esses achados corroboram as evidencias de Silva Aguiar et al (2016). Por outro lado, os resultados de Santos et al (2019) mostraram que a idade é negativamente associada ao excesso de confiança e, quanto mais velho, menor era o excesso de confiança dos indivíduos. 
Também foi realizada uma análise entre os cursos que tiveram maior representatividade na amostra, sendo eles: Ciências Contábeis ( $n t$ igual a 123, 61, 114, 68, 72 e 222, respectivamente), com 60 alunos, Agronomia ( $n t$ igual a 84, 54, 64, 52, 64 e 111, respectivamente), com 39 alunos, Educação Física ( $n t$ 60, 33, 49, 32, 27 e 96, respetivamente), com 29 alunos e Direito ( $n t$ igual a 56, 36, 24, 22, 18 e 75, respectivamente) e Engenharia Química (nt igual a 62, 20, 18, 24, 25 e 82, respectivamente) com 21 alunos cada, representando, juntos, 63\% dos alunos participantes da pesquisa. Com relação a acuidade, os alunos de Agronomia se destacaram, 56,64\% de respostas corretas, seguidos dos alunos de Ciências Contábeis, 48,88\%. Dentre os alunos menos acurados estão os Educação Física, com 39,51\%.

Tabela 5 - Média da Acuidade, Calibração e Excesso de Confiança dos cursos mais representativos da amostra

\begin{tabular}{lcccc}
\multicolumn{1}{c}{ Cursos } & $\boldsymbol{N}$ & $\begin{array}{c}\text { Acuidade } \\
\text { (Proporção de } \\
\text { respostas corretas) }\end{array}$ & $\begin{array}{c}\text { Calibração } \\
\text { (Lichtenstein et al. } \\
\mathbf{1 9 8 2}\end{array}$ & $\begin{array}{c}\text { Excesso de } \\
\text { confiança } \\
\text { (Murphy, 1973) }\end{array}$ \\
\hline Ciências Contábeis & 660 & $48,88 \%$ & $30,58 \%$ & $30,58 \%$ \\
\hline Agronomia & 429 & $56,64 \%$ & $31,00 \%$ & $39,57 \%$ \\
\hline Educação Física & 297 & $39,51 \%$ & $64,27 \%$ & $74,71 \%$ \\
\hline Direito & 231 & $40,10 \%$ & $55,38 \%$ & $65,60 \%$ \\
\hline Engenharia Química & 231 & $40,91 \%$ & $51,71 \%$ & $56,22 \%$ \\
\hline
\end{tabular}

Fonte: Dados da pesquisa

Em referência a calibração média, os alunos do curso de Educação Física foram os mais calibrados em seus julgamentos, 64,27\%, seguidos dos alunos de Direito, que obtiveram uma calibração média de 55,38\%. O curso cujos alunos foram menos calibrados foi Ciências Contábeis, que obteve um índice de calibração médio de 30,58\%. Com relação ao excesso de confiança média, o curso de Educação Física obteve um grau relevante em relação aos outros cursos, sendo 74,71\%, sendo os alunos de Ciências Contábeis os que apresentaram o menor índico desse viés, 30,58\%. Nos resultados de Silva Aguiar (2016), não foram encontradas evidencias significativas que pudessem comprovar a relação entre a formação e o excesso de confiança.

\section{$5 \quad$ Recomendações Finais}

A presente pesquisa verificou a relação entre a capacidade cognitiva de julgamento de profissionais já estabelecidos no mercado e estudantes de graduação no tocante ao excesso de confiança em seus julgamentos, tendo como hipótese o pressuposto de que os profissionais de mercado são mais excessivamente confiantes que os estudantes de graduação. Para alcançar o objetivo da pesquisa, foi aplicado um questionário com perguntas de conhecimento geral, popularmente conhecidas como questões de almanaque, onde os sujeitos respondiam "Sim" ou "Não" e estabeleciam a confiança na resposta dada para cada questão. A amostra contou com 424 indivíduos, dos quais 270 eram estudantes de graduação e 154 profissionais de mercado.

Aplicando-se a metodologia de Murphy (1973), derivada do Score Brier, para cálculo do excesso de confiança, verificou-se que a hipótese foi confirmada. Os profissionais tiveram um excesso de confiança 7,13\% maior que os estudantes. No entanto, a calibração no julgamento dos profissionais foi somente $3,73 \%$ maior, ou seja, houve uma maior correspondência entre as estimativas de confiança $(0,5<r t<1,0)$ marcadas pelos profissionais e os resultados corretos obtidos. Mesmo os profissionais sendo mais confiantes que os estudantes, os dois grupos apresentaram esse viés, sendo 57,15\% e 50,02\% para cada um deles, nessa ordem.

A qualificação dos profissionais não se mostrou uma variável significativa para julgamentos excessivamente confiantes como defende a literatura. Os profissionais com graduação obtiveram um excesso de confiança maior $(61,14 \%)$ do que profissionais com especialização $(54,8 \%)$ e profissionais com pós-doutorado obtiveram um excesso de confiança menor (76\%) do 
que os com doutorado $(78,43 \%)$. Os participantes do gênero feminino foram significativamente mais confiantes $(62,34 \%)$ e mais calibradas $(48,68 \%)$ do que os participantes do gênero masculino, $50,54 \%$ e $42,93 \%$, respectivamente. Dessa forma, no que se refere a qualificação e a diferença entre o gênero feminino e masculino a presente pesquisa rejeitou os achados de uma parte relevante da literatura sobre o tema, como Barber e Odean (2001), Ferreira e Yu (2003), Zindel (2008) e Lima Filho, Bruni e Sampaio (2012), os quais defendem que o grau de qualificação é diretamente proporcional ao excesso de confiança e que indivíduos do gênero feminino possuem menos excesso de confiança e são mais calibradas.

Na relação entre idade e excesso de confiança, verificou-se que os indivíduos que tinham entre 17 e 24 nos obtiveram um excesso de confiança menor $(53,63 \%)$ do que os participantes com idades entre 25 e 63 anos, 55,13\%. Apesar disso, os dois grupos obtiveram baixa confiança na categoria de $50 \%,-1,58 \%$ e - 1,16\%, respectivamente. Entre os cursos que contaram com uma maior representatividade na pesquisa (Ciências Contábeis, Agronomia, Educação Física, Direito e Engenharia Química, respectivamente) os estudantes do curso de Educação Física foram os que mais se mostraram excessivamente confiantes, $74,71 \%$, seguido dos estudantes do curso de Direito, 65,6\%, e por último os do curso de Ciências Contábeis, com 30,58\%. Na relação entre dificuldade e excesso de confiança, a presente pesquisa confirmou que essas duas variáveis são diretamente proporcionais.

Um dado significativo encontrado na pesquisa foi que em diversos casos, conforme metodologia da Fórmula 3.2 (Excesso/Falta de Confiança), houve baixa confiança para a categoria de 50\%, haja vista os sinais negativos encontrados. Aliado a isso, os altos índices de excesso de confiança na categoria de $100 \%$ exerceram grande influência nas medidas de determinados grupos. A consequência disso é que os sujeitos apresentavam excesso de confiança médio alto em detrimento de uma única categoria que exerceu uma forte influência na média. Tal fato ocorreu para os estudantes do curso de Educação Física, para os indivíduos entre 25 e 63 anos, para estudantes do gênero feminino da área de Humanidades, para profissionais do gênero feminino da área de Ciências da Vida, para estudantes do gênero masculino das áreas de Ciências da Vida e Humanidades e para profissionais do gênero masculino da área de Humanidades. Esses resultados são compatíveis com as alegações de Plous (2003) de que as medidas do excesso de confiança podem ser enganosas em determinados casos.

É importante refletir se os profissionais possuem maior excesso de confiança que os alunos graduandos, em qual momento essa confiança aumenta a ponto de não corresponder mais com a realidade, uma vez que todos os profissionais, em algum momento da vida, foram estudantes e em suas trajetórias acadêmicas e profissionais suas confianças gerais foram mudando. $\mathrm{O}$ que se pode sugerir, de acordo com a presente pesquisa e com a literatura, é que um indivíduo, ao saber que possui um bom conhecimento e anos de experiência, considerar essa experiência como único fator determinante para sua declaração de confiança, sem considerar outras variáveis como a tecnologia e o acesso a informações em meio digital que, em muitos casos, são absorvidos pelos mais jovens.

No mais, sugere-se para pesquisas futuras agrupar a idade dos estudantes e profissionais, por exemplo, estudantes de 17 a 22 anos e profissionais de 30 a 50 anos, de forma a tentar diminuir o desvio padrão encontrado na idade dos estudantes e profissionais participantes da presente pesquisa; verificar o excesso de confiança relacionado a cada questão; elaborar uma relação do excesso de confiança entre os profissionais de mercado e estudantes de graduação pela metodologia do Score Brier; estabelecer uma relação entre a Teoria da Prospecto e o excesso de confiança entre profissionais de mercado e estudantes de graduação; e verificar se o uso do feedback após cada avaliação de probabilidade diminuiria o significativo excesso de confiança entre profissionais e alunos. 


\section{Referências}

BARROS, L. Decisão de financiamento e de investimento das empresas sob a ótica de gestores otimistas e excessivamente confiantes. $261 \mathrm{f}$. Tese de doutorado do Programa de Pós graduação em Administração da Universidade de São Paulo, 2005. DOI: 10.11606/T.12.2005.tde-07082007224658.

\section{BELKAOUI, A. Behavioral management accounting. Londres: Quorum Books, 2002}

BOHNER, G.; RANK, S.; REINHARD, M.A.; EINWILLER, S.; ERB, H.P. Motivational determinants of systematic processing: expectancy moderates effects of desired confidence on processing effort. European Journal of Social Psychology, Vol. 28, p. 185-206, 1998. DOI: 10.1002/1099-0992.

BRIER, G.W. Verification of forecasts expressed in terms of probability. Monthly Weather Review, January, 1950.

COMITÊ DE PRONUNCIAMENTOS CONTÁBEIS - CPC 00. Conselho Federal de Contabilidade, p. 10, 2012.

DUNNING, D.; GRIFFIN D.W.; MILOJKOVIC, J.D.; ROSS, L. The overconfidence effect in social prediction. Journal of personality and social psychology, v. 58, n. 4, p. 568, 1990. DOI: 10.1037/0022-3514.58.4.568.

ERCEG, N.; GALIC, Z. Overconfidence bias and conjunction fallacy in predicting outcomes of football matches. Journal of Economic Psychology, 2014. DOI: 10.1016/j.joep.2013.12.003.

FAMA, E. Efficient Capital Markets: A Review of Theory and Empirical Work. The Jornal of Finance, v. 25. No. 2, p. 383-417, 1970. DOI: 10.1111/j.1540-6261.

FERREIRA, C.F.; YU, A.S.O. Todos acima da média: excesso de confiança em profissionais de finanças. Revista de Administração, v.38, p. 101-111, 2003.

FREITAS, AU de. Avaliando o Comportamento de Gestor Especialista em Ações Sob a Ótica de Behavioral Finance. Faculdade de Economia e Finanças-IBMEC.. Dissertação de Mestrado. Rio de Janeiro, 2006.

GRIFFIN, D.; TVERSKY, A. The weighing of evidence and the determinants of confidence. Cognitive psychology, v. 24, n. 3, p. 411-435, 1992. DOI: 10.1016/0010-0285.

KAHNEMAN, D. Maps of bounded rationality: Psychology for behavioral economics. The American Economic Review, v. 93, n. 5, p. 1449-1475, 2003. DOI: $10.1257 / 000282803322655392$.

KAHNEMAN, D.; RIEPE, M. W. Aspects of investor psychology. Journal of Portfolio Management, v. 24, n. 4, p. 52-65, 1998. DOI: 10.3905/jpm.1998.409643.

KAHNEMAN, D. Thinking, Fast and Slow, Farrar, Straus and Giroux, New York, 2012 
KAHNEMAN, D.; TVERSKY, A. On the reality of cognitive illusions. Psychological Review, v. 103, n. 3, p. 582-591, 1996. DOI: 10.1037/0033-295X.103.3.582.

KAHNEMAN, D.; TVERSKY, A. Prospect Theory: An Analysis of Decision under Risk. Econometrica, v. 47, p. 263-291, 1979. DOI: 10.1142/9789814417358.

KAHNEMAN, D.; TVERSKY, A. Subjective probability: A judgment of representativeness. Cognitive Psychology, v. 3, p. 430-454, 1974. DOI: 10.1016/0010-0285.

KIMURA, H. Aspectos comportamentais associados às reações do mercado de capitais. RAEeletrônica, v. 2, n. 1, jan./jun. 2003. DOI: 10.1590/S1676-56482003000100007.

LICHTENSTEIN, S.; FISCHHOFF, B.; PHILLIPS, L. D. Calibration of probabilities. The state of the art to 1980. Organizational Behaviour and Human Performance, p. 275-324, 1982.

LICHTENSTEIN, S.; FISCHHOFF, B. Do those who know more also know more about how much they know? The calibration of probability judgments. Organizational Behavior and Human Performance, v. 20, p. 159-183, 1977. DOI: 10.1016/0030-5073.

LIMA FILHO, Raimundo; BRUNI, Adriano Leal; SAMPAIO, Márcio. A Influência do Gênero, Idade e Formação na Presença de Heurísticas EM Decisões de Orçamento: Um Estudo Quase experimental. Revista Universo Contábil, v. 8, n. 2, p. 103-117, 2012. DOI: 10.4270/ruc.2012215.

LUCENA, E. Análise da relação entre a capacidade cognitiva e a ocorrência dos vieses cognitivos da representatividade no julgamento. Tese. (Doutorado em Ciências Contábeis). Programa Multi-institucional e inter-regional de Pós-graduação em Ciências Contábeis. Universidade Federal do Rio Grande do Norte, 2015.

MILANEZ, D.Y. Finanças comportamentais no Brasil. Dissertação de Mestrado em Economia das Instituições e do Desenvolvimento, Faculdade de Economia, Administração e Contabilidade da Universidade de São Paulo, São Paulo, 2003.

PIMENTA, D. P.; BORSATO, J. M. L. S.; RIBEIRO, K. C. Um estudo sobre a influência das características sociodemográficas e do excesso de confiança nas decisões dos investidores, analistas e profissionais de investimento à luz das Finanças Comportamentais. REGE-Revista de Gestão, v. 19, n. 2, p. 263-280, 2012. DOI 10.57/rege462.

PLOUS, S. The psychology of judgment and decision making. McGraw-Hill, 1993.

SAMPAIO, Márcio Santos et al. Excesso de confiança e Controladoria: Um estudo envolvendo práticas orçamentárias. Revista de Finanças Aplicadas, v. 1, p. 20, 2012.

SANTOS, João Victor Joaquim et al. Fatores Determinantes do Grau de Excesso de Confiança dos Estudantes de Ciências Contábeis. Revista Contabilidade e Controladoria, v. 11, n. 1, 2019. DOI: $10.5380 /$ rcc.v11i1.54092.

SHIMIZU, T. Decisão nas Organizações. 2 ed. São Paulo: Atlas, 2006. 
SILVA AGUIAR, Elizabeth et al. A influência de gênero, idade, formação e experiência nas decisões de investimentos: uma análise do efeito confiança. Revista Evidenciação Contábil \& Finanças, v. 4, n. 3, p. 44-55, 2016. DOI: 10.18405/recfin20160303.

ULRICH, N. Cognitive psychology. Appleton-Century-Crofts, New York, 1967.

ZAKAY, D.; TSAL, Y. The impact of using forced decision-making strategies on post-decisional confidence. Journal of Behavioural Decision Making, v. 63, 1993. DOI: 10.1002/bdm.3060060104.

ZINDEL, M. T. L. Finanças Comportamentais: o viés cognitivo excesso de confiança em investidores e sua relação com as bases biológicas. Tese de Doutorado em Engenharia de Produção. Florianópolis: Programa de Pós-Graduação em Engenharia da Produção, Universidade Federal de Santa Catarina, 2008.

YATES, J. F.; LEE, J.; SHINOTSUKA, H. Beliefs about Overconfidence, Including Its CrossNational Variation. Organizational Behavior and Human Decision Processes, 1996. DOI: 10.1006/obhd.1996.0012.

YOSHINAGA, C.E; OLIVEIRA, R.F.; SILVEIRA, A.D.M.; BARROS, L.A.B.C. Finanças comportamentais: uma introdução. REGE Revista de Gestão, v. 15, n. 3, p. 25-35, 2008. DOI: 10.5700/ISSN.2177-8736.

* Uma versão preprint do artigo foi apresentada no XII Congresso ANPCONT, 2018. 